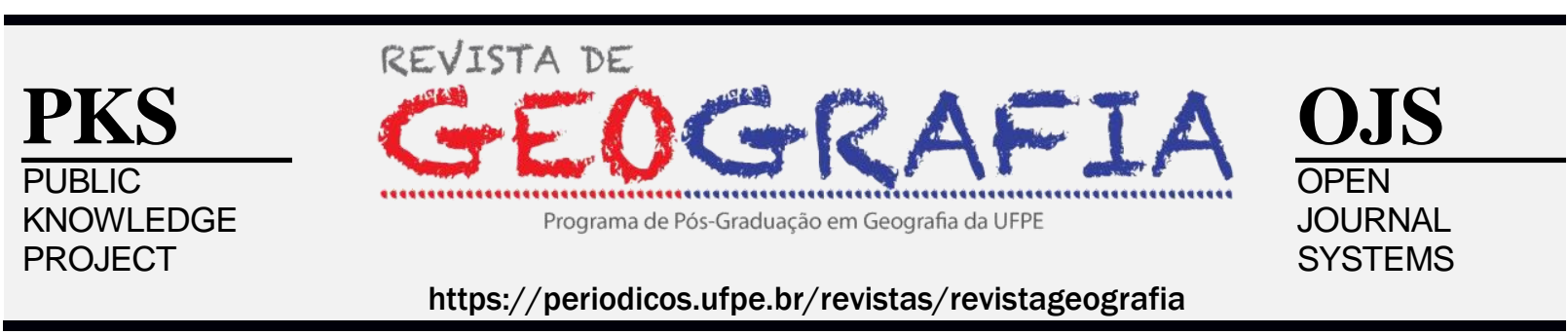

\title{
VARIABILIDADE DECADAL DA PRECIPITAÇÃO E TEMPERATURA MÍNIMA DO AR VISANDO O DESENVOLVIMENTO AVÍCOLA EM SÃO BENTO DO UNA - PE, BRASIL
}

\author{
Raimundo Mainar de Medeiros
}

${ }^{1}$ Meteorologista, Pós-Doutor, Universidade Federal Rural de Pernambuco. E-mail: mainarmedeiros@gmail.com

Artigo recebido em 25/01/2019 e aceito em 25/12/2019

\begin{abstract}
RESUMO
A precipitação é a variável climática de maior importância e com a maior variabilidade espaço temporal, em particular na região semiárida. Além das oscilações diárias, a temperatura do ar varia também ao longo do ano e o ser humano e animal tenta se adaptar as suas flutuações. Objetiva-se analisar a variabilidade decadal utilizando-se de séries temporais da precipitação e temperatura mínima do ar visando como base à crise hídrica no município de São Bento do Una. Os dados pluviométricos foram adquiridos da Superintendência do Desenvolvimento do Nordeste e da Agencia Pernambucana de Água e Clima, compreendido entre os anos de 1920 a 2016. Utilizou-se de cálculos simplificados estatisticamente para definir, média, desvio padrão, coeficiente de variância, máximos e mínimos valores absolutos ocorridos, definiu-se a quadra chuvosa e seca. Os valores da temperatura mínima do ar foram estimadas pelo software Estima_T para o mesmo período da precipitação. A importância desse estudo em gerar subsídios para criação de medidas mitigadoras para a área de estudo em relação à avicultura, agropecuária, armazenamento e represamento de água e a população em geral. As contribuições locais como Zona de Convergência Intertropical, atuaram com intensidade e provocaram em suas maiorias chuva acima da normalidade em algumas décadas, registrando-se desastres de moderada a intensa proporção.
\end{abstract}

Palavras chaves: Flutuações e oscilações climáticas, mudanças climáticas, fenômenos adversos

\section{DECADAL VARIABILITY OF PRECIPITATION AND MINIMUM AIR TEMPERATURE FOR AVOCOL DEVELOPMENT IN SÃO BENTO DO UNA - PE, BRAZIL}

\begin{abstract}
Precipitation is the most important climatic variable and with the greatest temporal space variability, particularly in the semi-arid region. Besides the daily oscillations, the temperature of the air also varies throughout the year and the human being and animal tries to adapt its floats. The objective of this study was to analyze decadal variability using time series of precipitation and minimum air temperature, aiming at the water crisis in the municipality of São Bento do Una. The rainfall data were acquired from the Northeast Development Authority and the Pernambuco Water and Climate Agency, from 1920 to 2016. Statistically simplified calculations were used to define mean, standard deviation, coefficient of variance, maximum and minimum absolute values occurred, the rainy and dry block was defined. The values of the minimum air temperature were estimated by the software Estima_T for the same period of precipitation. The importance of this study in generating subsidies to create mitigating measures for the study area in relation to poultry farming, agriculture, water storage and water retention and the population in general. Local contributions, such as the Intertropical Convergence Zone, acted intensely and caused in their majorities rainfall above normal in a few decades, with disasters of moderate to intense proportions.
\end{abstract}

Key words: Climate fluctuations and fluctuations, climatic changes, adverse phenomena.

INTRODUÇÃO 
Nas últimas décadas, as alterações climáticas e suas consequências para a humanidade, tem sido uma das maiores preocupações dos cientistas de todo o mundo. Principalmente no tocante aos fatores responsáveis pela variabilidade climática, que vêm se acentuando desde meados do século XX. As atividades humanas são, na visão de alguns pesquisadores, as responsáveis por parte destas mudanças. Entretanto, deve-se levar em consideração, uma possível variabilidade climática natural, uma vez que a magnitude do sinal associada à ela nos registros climáticos existentes, ainda não foi bem determinada (IPCC, 1996; 2001).

O semiárido nordestino com o passar dos anos, vem configurando-se como um importante laboratório, possibilitando diversos estudos sobre a precipitação pluviométrica, tendo em vista a alta variabilidade espacial e temporal desta variável de acordo com Costa (2013).

Segundo Aragão (1975), a principal razão da existência do semiárido nordestino é a ausência de um mecanismo dinâmico que provoque movimentos ascendentes.

Em conformidade com Cavalcanti et al. (2011) os movimentos ascendentes que ocorrem de forma rápida e o calor liberado para que a umidade seja condensada irá provocar movimentos de cima para baixo diferenciados e excepcionais em outras partes da atmosfera nos trópicos, o que contribui para explicar a pouca formação de nuvens e a diminuição da precipitação, provocando episódios de seca moderada a grave no Nordeste do Brasil

Secas prolongadas tornam a água um recurso indisponível e até escasso provocando a migração da população para outras regiões em busca de melhores condições de sobrevivência de vida. A falta de precipitação atrapalha o desenvolvimento agropecuário trazendo consequências negativas para a economia da região. Nas plantas, a falta de água prejudica o seu desenvolvimento em suas diversas fases de crescimento, principalmente, quando este problema ocorre durante fases fenológicas nas quais elas necessitam de maiores quantidades de água, como, por exemplo, durante a floração e frutificação de acordo com Fietz et al. (1998). Outras problemáticas esperadas, segundo as projeções dos estudos de mudanças climáticas, são as reduções dos índices pluviométricos que poderão atingir uma faixa de $60 \%$ dos valores mensais, com isto os reservatórios de armazenamento de águas ficarão obsoletos restringindo ainda mais a água potável para a sobrevivência humana, animal e vegetal, como a faunas e a flora, podendo algumas espécies entrar em extinção em conformidade com Marengo et al. (2011). 
Medeiros (2012) analisou a climatologia da precipitação no município de Bananeiras - PB, no período de 1930-2011 como contribuição à Agroindústria e constatou que os índices pluviômetros são essenciais à sustentabilidade agroindustrial.

Os seres vivos que povoam o planeta vivem adaptados à energia solar do ambiente. Além de oscilações diárias, a temperatura do ar varia também ao longo do ano, conforme a disposição do relevo e da latitude, que influencia na distribuição da radiação solar. A temperatura do ar tem um efeito claro no desenvolvimento dos seres vivos, uma vez que essa é um dos mais importantes elementos meteorológicos, pois traduz os estados energéticos e dinâmicos da atmosfera e consequentemente revela a circulação atmosférica, sendo capaz de facilitar e/ou bloquear os fenômenos atmosféricos em conformidade com Dantas et al. (2000).

A temperatura do ar expressa a energia contida no meio. No decorrer de um dia a energia que existe à disposição do ambiente oscila entre dois valores extremos, ou seja, entre a temperatura mínima e a máxima. Como essa energia vai de um extremo ao outro, ela atua no continuo estimulo aos processos fisiológicos vitais nos seres vivos, a exemplo do desenvolvimento e crescimento das espécies vegetais, como: transpiração, respiração, germinação, crescimento, floração e frutificação. Em cada estágio de desenvolvimento da planta existem faixas adequadas de temperaturas para perfeito desenvolvimento conforme Costa et al. (2011).

Mello et al. (2015) analisaram a variabilidade climática da temperatura máxima, média e mínima do estado de Pernambuco, enfocando tais variações como um meio para compreender futuras mudanças. Utilizaram dados de temperatura anuais no período de 1960 a 1990. Afirmaram que o conhecimento do comportamento climático de uma região é importante para estudos de previsão do tempo e principalmente para o planejamento agropecuário, contribuindo com informações ao homem do campo para não realizar queimadas na hora do preparo das terras para o plantio, evitando desta forma que aumento do referido parâmetro ocorra. A delimitação de um período mais quente ou mais frio serve de alerta às autoridades federais, estaduais e municipais e tomadores de decisões, com objetivo de melhor planejamento.

Medeiros et al. (2012) calcularam a temperatura do ar média diária com o emprego de diferentes metodologias para os municípios de Parnaíba, Picos e Gilbués localizados, respectivamente, na área litorânea, na região central e pertencente à região semiárida, em terras do cerrado e desertificada do Estado do Piauí Utilizaram cinco métodos para o cálculo da temperatura média diária do ar, adotando como padrão o recomendado pelo Instituto Nacional 
de Meteorologia (INMET). Os quatro métodos avaliados em relação ao padrão possuíram desempenho classificado como "Muito bom e Ótimo", com índice de confiança variando entre 0,83 a 0,98 . Os resultados ainda indicam que nas condições climáticas da região de estudo os quatro métodos avaliados em relação ao padrão (INMET) podem ser utilizados nas estimativas das temperaturas médias diárias do ar.

Nogueira et al. (2012) e Correia et al. (2011) concordaram que a temperatura do ar se destaca entre as variáveis atmosféricas mais utilizadas no desenvolvimento de estudos de impactos ambientais com mudanças nos processos meteorológicos e hidrológicos.

Em conformidade com Marengo et al. (2007), a amplitude térmica para Região Sul do Brasil apresentou tendências negativas no período de 1960-2002, indicando que as temperaturas mínimas foram mais intensas que as máximas, especialmente no verão. Rusticucci et al. (2004), indicaram tendências negativas na amplitude térmica diurna, devido a variações positivas das tendências da temperatura mínima. De acordo com as análises de Marengo et al. (2007), o aquecimento observado parece ser mais intenso no inverno que no verão, o que provavelmente está relacionado ao aumento do número de dias quentes no inverno de acordo com Campos (2010).

Ometto (1981) e Pereira et al. (2002) mostraram que os índices das temperaturas máximas e mínimas do ar permanecem integrados à disponibilidade da energia solar, da cobertura de nuvem, da umidade relativa do ar e do solo, do vento (direção e intensidade) e dos parâmetros geográficos como orografia, altitude e latitude local.

A temperatura média do ar, precipitação pluvial, umidade relativa do ar e evaporação estão relacionadas à agricultura por sua importância junto aos processos climáticos insolação são alvo de pesquisas especialmente. São os elementos meteorológicos que exercem influência direta sobre as condições agrícolas em conformidade com Amorim et al. (2004).

A ocupação dos ecossistemas para o desenvolvimento da agropecuária e principalmente o avícola vem se intensificando no Brasil e em especial no estado do Pernambuco, tornando assim um motivo de grande preocupação no que se refere ao desmatamento e ocupação da área do município de São Bento do Una. Esta ocupação se intensificou devido à expansão da fronteira avícola para produção de carne e ovos destinados à exportação e ao consumo interno, (FRANCO 2007). Desde então, o município estudado passou a se caracterizar como áreas de elevado potencial para expansão avícola. 
Considerando que de acordo com dados da AVIPE (2005) - Associação de Avicultura de Pernambuco a cidade de São Bento do Una possui como principais atividades econômicas a agropecuária e a avicultura, atividades caracterizadas por gerar grandes impactos ambientais, merecendo destaque ao elevado consumo de água. Segundo ainda a AVIPE a avicultura é um setor importantíssimo para a população, contribuindo como fornecedora de alimentos em especial a proteína animal. Surgiu o interesse de verificar a produção avícola que ultimamente vêm ganhando em pequenos municípios, e analisar a crise hídrica que vem ocorrendo nos últimos anos deixando os avicultores preocupados com abastecimento e armazenamento de água para seus animais.

O uso sustentável da água não deve ser uma prioridade apenas do setor agrícola e das regiões onde já se observam a escassez de água, ele deve uma prioridade de todos os setores da economia e regiões de acordo com Pedde et al. (2013). A distribuição da precipitação pluvial no nordeste brasileiro é bastante irregular no tempo e no espaço, além disso, as estações chuvosas ocorrem de forma diferenciada, em quantidade, duração e distribuição.

Objetiva-se analisar a variabilidade decadal utilizando-se de séries temporais da precipitação e temperatura mínima do ar visando como base o desenvolvimento avícola no município de São Bento do Una.

\section{MATERIAL E MÉTODO}

São Bento do Una localiza-se na mesorregião Agreste e na Microrregião do Vale do Ipojuca do Estado de Pernambuco, limitando-se a norte com Belo Jardim, a sul com Jucati, Jupi e Lajedo, a leste com Cachoeirinha, e a oeste com Capoeiras, Sanharó e Pesqueira. 


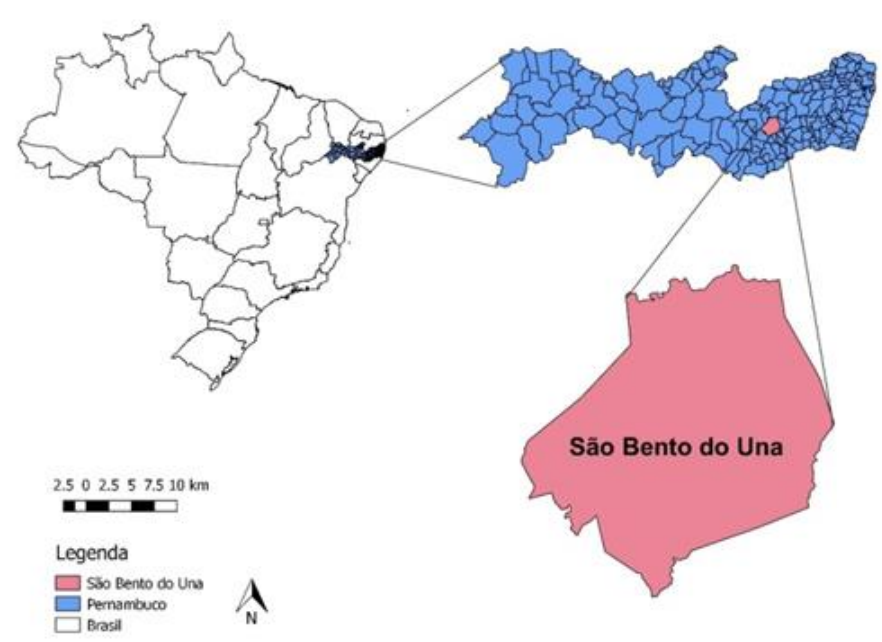

Figura 1. Localização do município de São Bento do Una no estado do Pernambuco.

A área municipal ocupa $719,15 \mathrm{~km}^{2}$ e representa $0.72 \%$ do Estado de Pernambuco. A sede do município tem altitude de 614 metros e coordenadas geográficas de $08^{\circ} 31$ '22” de latitude sul e $36^{\circ} 06^{\prime} 40^{\prime \prime}$ de longitude oeste. Com população estimada de 58.251 habitantes com densidade demográfica de $74,03 \mathrm{hab} / \mathrm{km}^{2}$.

Segundo a classificação climática por Köppen (1928) São Bento do Una tem o clima As Tropical Chuvoso, com verão seco, esta classificação está de acordo com Alvares et al. (2014) e com Medeiros et al. (2018).

A quadra chuvosa se inicia em fevereiro com chuvas de pré-estação (chuvas que antecedem o período chuvoso) com seu término ocorrendo no final do mês de agosto e podendo se prolongar até a primeira quinzena de setembro. Com uma média de 74,7 mm O trimestre chuvoso centra-se nos meses de março, abril e maio com índices pluvial de 85,6 mm e os seus meses seco ocorrem entre setembro, outubro e novembro com uma média pluvial de 20,1 mm. Os fatores provocadores de chuvas no município são a contribuição da Zona de Convergência Intertropical (ZCIT), formação dos vórtices ciclônicos de altos níveis (VCAS), contribuição dos ventos alísios de nordeste no transporte de vapor e umidade a quais condensam e forma nuvens provocando chuvas de moderadas a fortes, formações das linhas de instabilidades, orografia e suas contribuições local e regional formando nuvens e provocando chuvas de moderada a forte segundo Medeiros (2016). Salienta-se que a atuação da ZCIT pouco contribui para as ocorrências das chuvas em seu período chuvoso, excetos em caso de eventos extremos como registrados nos anos de 1921,1924, 1940, 1966, 1972, 1975, 1985, 1995 e 2009 que se 
registraram índices pluviais oscilando de $780 \mathrm{~mm}$ a 1079,9 mm com durações de chuvas em 1 hora e vinte minutos. E com oscilações pluviais entre $350 \mathrm{~mm}$ a $200 \mathrm{~mm}$ têm-se os anos de 1933, 1993, 1998, 2012 e 2016 onde os fatores provocadores de chuvas não atingiram os valores climáticos.

Os dados de precipitação médias mensais utilizados compreende aos anos de 1920 a 2016, os quais foram adquiridos da Superintendência do Desenvolvimento do Nordeste (SUDENE, 1990), Agencia Pernambucana de Água e Clima (APAC, 2016) caracterizando um período de normal climatológica, onde, empregou-se do software em planilhas eletrônicas, para a realização dos cálculos simplificados estatisticamente como: média, desvio padrão, coeficiente de variância, máximos e mínimos valores absolutos, anomalia, totais anuais de precipitação ocorridos, onde definiu-se a quadra chuvosa e seca, plotando os seus respectivos gráficos e tendências.

A limitação dos recursos hídricos na atualidade é importante condicionante ao desenvolvimento econômico e social, acarretando inúmeros desafios ao planejamento e gerenciamento deste recurso em conformidade com Sousa et al. (2015). As falhas de dados ocorridas entre a década de 90 pode ser explicada pela troca de responsabilidade na coleta dos registros pluviométricos da antiga SUDENE para o LAMEPE, neste período de transição as estações passaram por manutenção e outras foram implantadas em algumas cidades dentre 1989 e 1992. Para tanto foram realizados preenchimentos de falhas, homogeneização e consistência nos referidos dados para pode-se trabalhar e fornecer informações confiáveis ao publico em geral.

Utilizaram-se valores da temperatura mínima do ar estimadas pelo software Estima_T (Cavalcanti e Silva, 1994; Cavalcanti et al., 2006). O Estima_T é um software para fazer estimativas de temperaturas do ar na Região Nordeste do Brasil. A referida região foi dividida em três áreas: sendo a área 1 que compreende os estados do Maranhão e Piauí; a área 2 especifica para os estado do Ceará, Rio Grande do Norte, Paraíba e Pernambuco e a área 3 para os estados da Alagoas; Sergipe e Bahia. Para cada região (1, 2 e 3) determinaram-se os coeficientes da função quadrática para as temperaturas média, máxima e mínima mensal em função das coordenadas locais: longitude, latitude e altitude de acordo com os autores Cavalcanti e Silva (2006) dada por:

$$
\mathrm{T}=\mathrm{C}_{0}+\mathrm{C}_{1} \lambda+\mathrm{C}_{2} \varnothing+\mathrm{C}_{3} \mathrm{~h}+\mathrm{C}_{4} \lambda^{2}+\mathrm{C}_{5} \varnothing^{2}+\mathrm{C}_{6} \mathrm{~h}^{2}+\mathrm{C}_{7} \lambda \varnothing+\mathrm{C}_{8} \lambda \mathrm{h}+\mathrm{C}_{9} \varnothing \mathrm{h}
$$




\section{RESULTADOS E DISCUSSÕES}

Em conformidade com o IPCC (2013) e Assad et al. (2008) e ainda com os estudos recentes, no Brasil e no mundo, sobre o aquecimento global e segurança alimentar indicam que a mudança climática pode afetar a produção de alimentos e fazer com que áreas de risco aumentem.

Figura 3 tem-se a variabilidade da precipitação e temperatura mínima decadal (19501959) para São Bento do Una. A variabilidade da temperatura mínima compreendido entre os meses de setembro a fevereiro oscilou entre $16,9{ }^{\circ} \mathrm{C}$ a $19{ }^{\circ} \mathrm{C}$ ao passo que no mesmo período (setembro-fevereiro) registraram-se precipitações reduzidas com oscilações fluindo entre 9,2 $\mathrm{mm}$ a $38,5 \mathrm{~mm}$. Nos meses de março a agosto registrou-se reduções gradativas das duas variáveis estudadas. As variações de temperatura foram entre $16,2{ }^{\circ} \mathrm{C}$ a $19,3{ }^{\circ} \mathrm{C}$ e as de precipitações ocorreram $29,1 \mathrm{~mm}$ a $78,3 \mathrm{~mm}$.

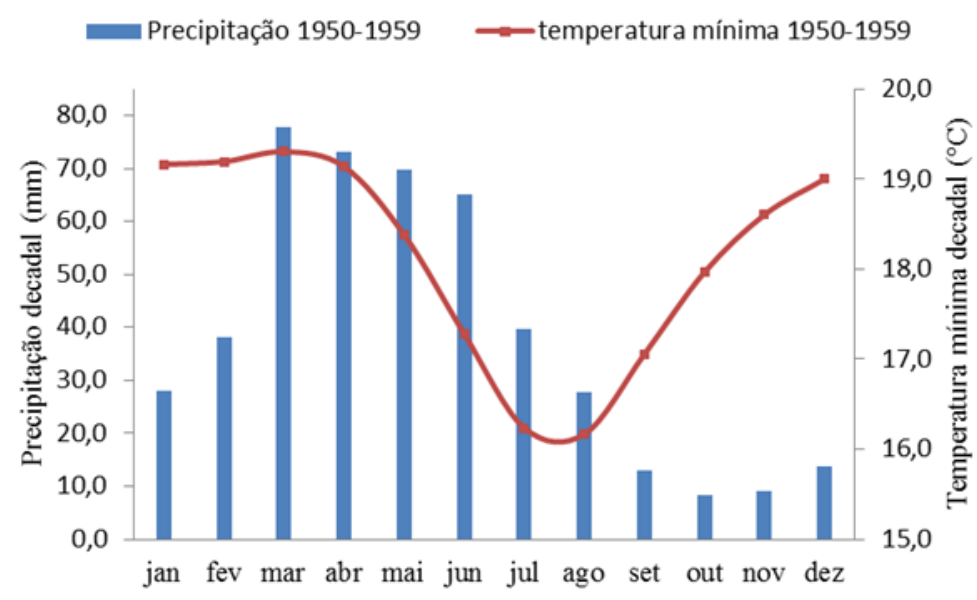

Figura 3. Precipitação e temperatura mínima decadal (1950-1959) para São Bento do Una.

Os meses de marco, julho os índices pluviais superaram as temperaturas mínimas, os meses de abril, junho e agosto chuvas e temperatura manteve equilíbrio, nos demais meses a variabilidade da temperatura foi superior aos índices pluviais (figura 4). Tais variabilidades estão de acordo com a citação de Aragão (1978). 


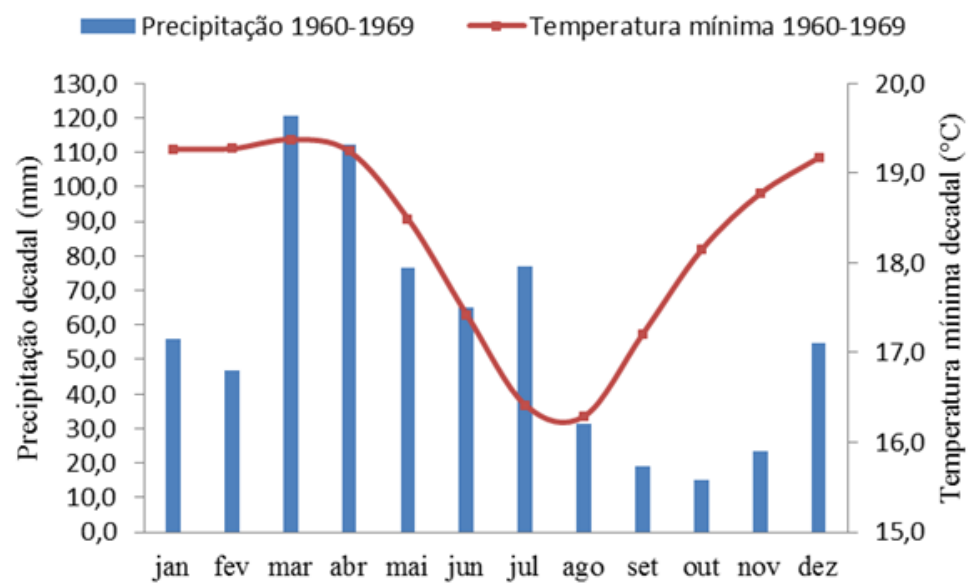

Figura 4. Precipitação e temperatura mínima decadal (1960-1969) para São Bento do Una.

Figura 5 tem-se as variabilidades pluviais e da temperatura mínima do ar para a década de 1970-1979. Nos meses de março, abril, junho e julho a flutuação da temperatura mínima foram abaixo dos índices pluvial sendo a condensação um fator de auxiliou para tal ocorrência. Nos demais meses ocorreu redução na variabilidade pluvial e aumento da temperatura exceto os meses de maio e agosto em que precipitação e temperatura mantiveram-se estabilizadas.

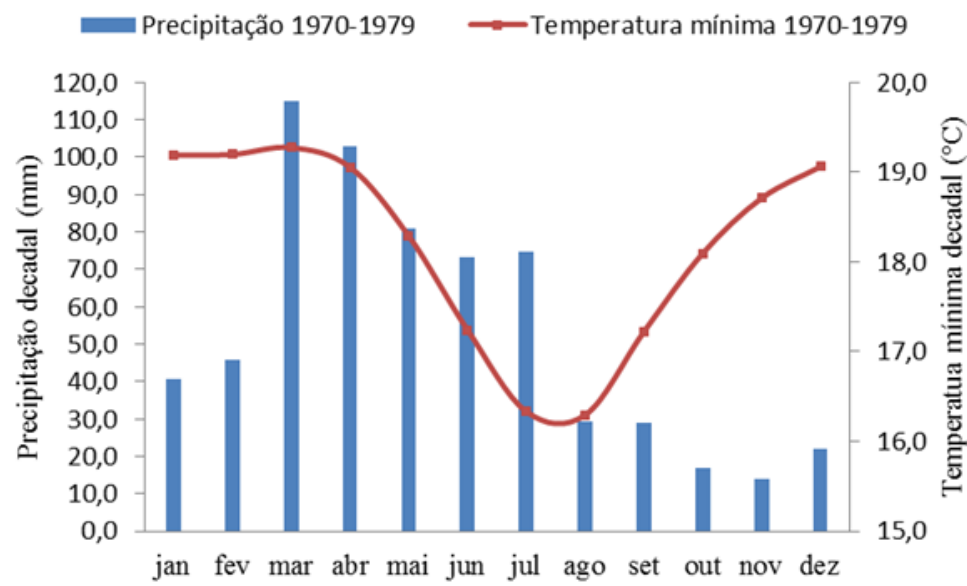

Figura 5. Precipitação e temperatura mínima decadal (1970-1979) para São Bento do Una.

Nota-se que a diminuição dos totais pluviométricos anuais é observada globalmente nas regiões tropicais entre $10^{\circ} \mathrm{S}$ e $10^{\circ} \mathrm{N}$, assim como o aumento da frequência da ocorrência de precipitações episódicas intensas associadas às mudanças climáticas globais de acordo com os autores Trenberth et al. (2007); Marengo et al. (2007). 
Tem-se temperatura mínima reduzida entre os meses de abril a agosto e ocorrências de chuvas moderadas, exceto para os meses de janeiro a março que ocorreram anomalias nos parâmetros estudados, Figura (6).

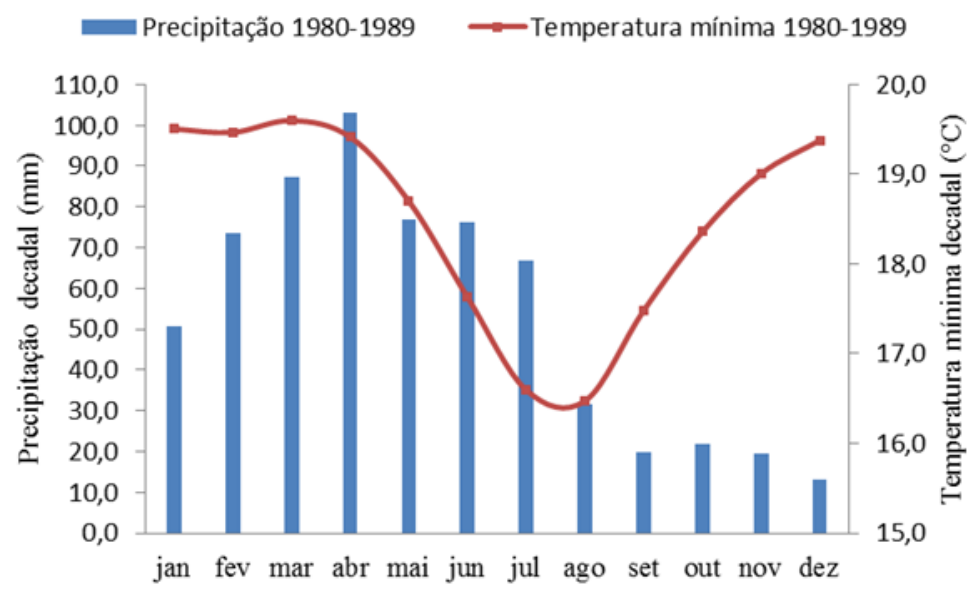

Figura 6. Precipitação e temperatura mínima decadal (1980-1989) para São Bento do Una.

Na Figura 7 observam-se as flutuações das precipitações e temperatura mínima decadal (1990-1999) para São Bento do Una. As mínimas temperaturas ocorreram nos meses de maio a agosto e oscilaram entre $18,8^{\circ} \mathrm{C}$ a $16,4^{\circ} \mathrm{C}$. Entre setembro a fevereiro registrou-se acréscimo de temperatura mínima e redução nos índices pluviais. Quando ocorre mecanismo dinâmico que provoque movimentos ascendentes formam-se as nuvens e precipitam de acordo com Aragão (1978).

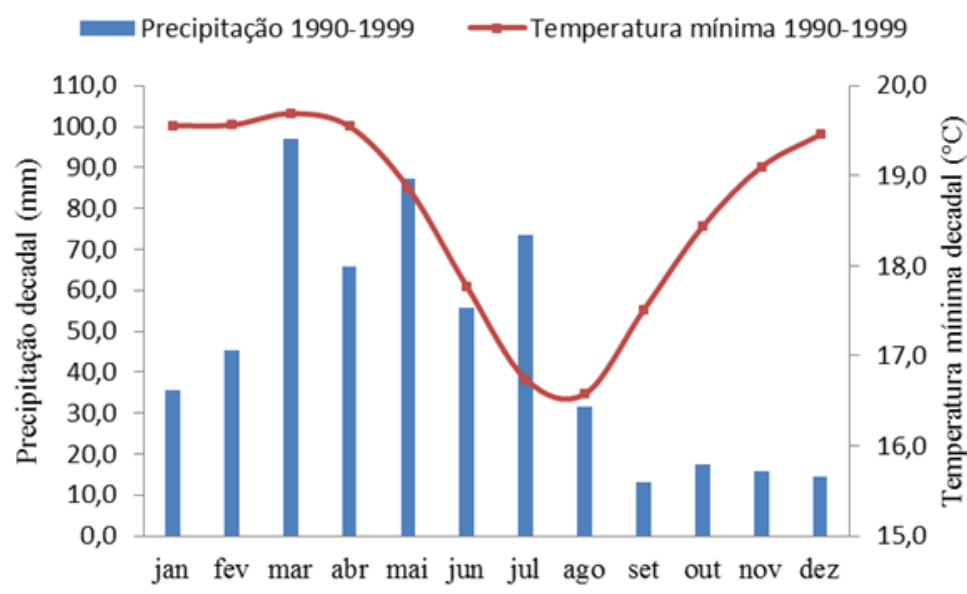

Figura 7. Precipitação e temperatura mínima decadal (1990-1999) para São Bento do Una.

As variabilidades da precipitação verso temperatura mínima do ar estão representadas na Figura 8. Destaca-se os meses de março, maio, junho, julho, agosto os quais apresentaram índices pluviais acima da normal e temperatura mínima abaixo da normalidade. Os Meses de 
janeiro, fevereiro, abril, setembro, outubro, novembro e dezembro os quais obtiveram baixa pluviometria e elevada temperatura mínima. Tal flutuabilidade foi observada por Brito et al. (2015) para a região Nordeste do Brasil.

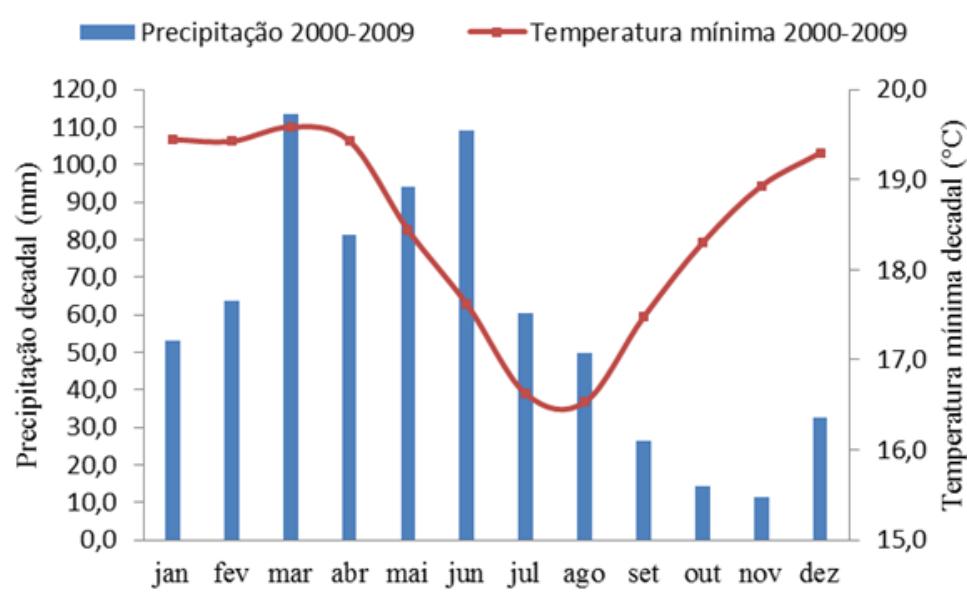

Figura 8. Precipitação e temperatura mínima decadal (2000-2009) para São Bento do Una.

No caso de Pernambuco, evidências de alterações climáticas já foram encontradas, mostrando que o aumento de temperatura do ar é crescente conforme relatam Lacerda et al. (2010). Este relatório, também, indica que todo o Brasil deverá ficar ao menos $3^{\circ} \mathrm{C}$ mais quente até o fim do século; as precipitações aumentariam em 30\% nas regiões Sul e Sudeste e diminuiriam em até $40 \%$ nas regiões Norte e Nordeste

Na Figura 9 tem-se a variabilidade da precipitação e temperatura mínima decadal (20102016) para São Bento do Una. Nos meses de maio a agosto ocorreu redução da temperatura mínima do ar e os índices pluviais foram elevados. Nos demais mês a verificou-se redução dos índices pluviais e aumento nas flutuações das temperaturas. Pode-se afirmar que esta faltando o nível de condensação para que ocorram precipitações e reduções de temperaturas.

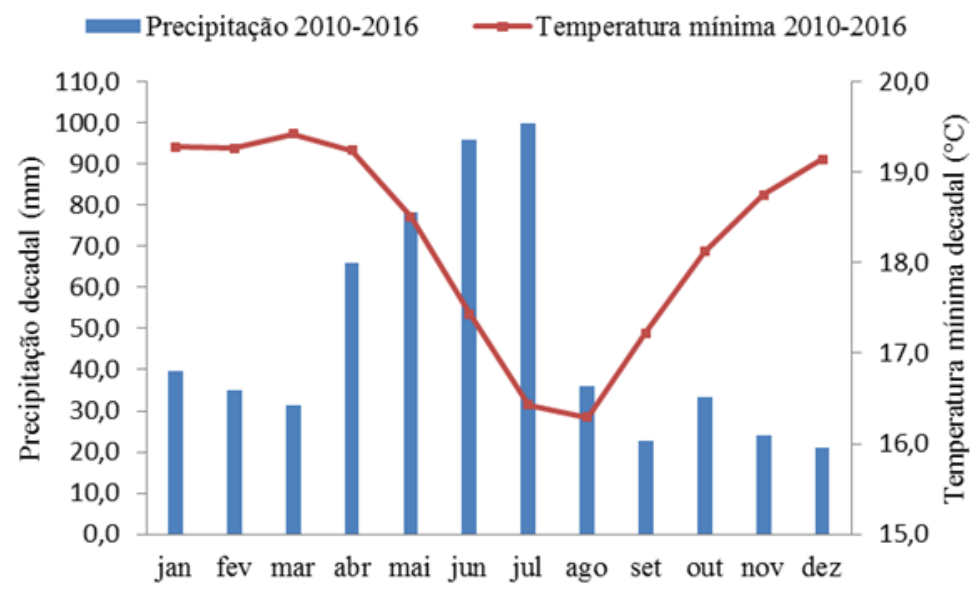


Figura 9. Precipitação e temperatura mínima decadal (2010-2016) para São Bento do Una.

Para Lima et al. (2011), quando a atmosfera local encontra-se estável, o efeito orográfico é restrito aos níveis mais baixos, mais próximos das montanhas e influi na distribuição da chuva. Quando instável, o efeito orográfico potencializa e redistribui o volume da precipitação por uma área maior. Para os autores, no Sudeste do Brasil, o principal responsável pela chuva orográfica parece ser o fluxo de ar, representado pela atuação dos sistemas atmosféricos regionais (ventos predominantes de sudeste), pela brisa marinha e pela própria instabilidade potencial da atmosfera circundante (convecção).

$\mathrm{Na}$ Tabela 1 verifica-se que os valores da média e da mediana foram desconexos, mostrando que houve a presença de valores extremos discordantes na amostra. O mês de máximo índice pluviométrico é março com 92,3 mm, os menores índices ocorrem entre os meses de setembro e outubro com 20,2 e 19,6 mm respectivamente destaca-se que a mediana apresentaram valores inferiores a média para o referido período, ao passo que nos meses de menores precipitações a mediana foi nula e apresentou valor insignificante, mostrando a dispersão contundente dos dados. As variabilidades mensais na mediana indicam que esta medida de tendência central pode não ser o valor mais provável de ocorrer nesse tipo de distribuição. É notável ainda, que as médias mensais superam os valores medianos em alguns meses. Visto assim, os modelos de distribuição de chuvas mensais são assimétricos, com coeficiente de assimetria positivo. Portanto a mediana apresenta maior probabilidade de ocorrência que a média, de acordo com os resultados deparados por Almeida et al. (2007).

Segundo Galvani (2011) o desvio padrão é importante para terem-se informações do "grau de dispersão dos valores em relação ao valor médio". O coeficiente de variância que é utilizado para fazer comparações em termos relativos e expressa "a variabilidade de cada conjunto de dados normalizada em relação à média, em porcentagem.”

Tabela 1. Medidas de tendência central e de dispersão na área municipal de São Bento do Ua PE.

\begin{tabular}{ccccccc}
\hline Meses & $\begin{array}{c}\text { Média } \\
(\mathrm{mm})\end{array}$ & $\begin{array}{l}\text { Desvio } \\
\text { Padrão(mm) }\end{array}$ & $\begin{array}{c}\text { Mediana } \\
(\mathrm{mm})\end{array}$ & $\begin{array}{c}\text { Coeficiente } \\
\text { Variância(mm) }\end{array}$ & $\begin{array}{c}\text { Precipitação } \\
\text { Máxima(mm) }\end{array}$ & $\begin{array}{c}\text { Precipitação } \\
\text { mínima(mm) }\end{array}$ \\
\hline Jan & 40,1 & 41,7 & 43,5 & 1,04 & 217,2 & 0,0 \\
Fev & 53,9 & 49,3 & 12,1 & 0,92 & 233,7 & 0,5 \\
Mar & 92,3 & 70,5 & 137,1 & 0,76 & 305,9 & 0,1 \\
Abr & 84,5 & 62,4 & 67,2 & 0,74 & 332,5 & 4,6
\end{tabular}




\begin{tabular}{ccccccc} 
Mai & 80,6 & 51,1 & 66,9 & 0,63 & 263,6 & 0,8 \\
Jun & 75,0 & 47,3 & 50,9 & 0,63 & 292,8 & 8,2 \\
Jul & 64,5 & 36,4 & 29,8 & 0,56 & 189,8 & 9,4 \\
Ago & 33,6 & 21,1 & 17,9 & 0,63 & 105,7 & 2,4 \\
Set & 20,2 & 18,7 & 8,4 & 0,69 & 112,6 & 0,0 \\
Out & 19,6 & 27,3 & 0,0 & 1,39 & 150,3 & 0,0 \\
Nov & 21,3 & 36,7 & 67,0 & 1,72 & 287,5 & 0,0 \\
Dez & 24,8 & 36,4 & 11,9 & 1,47 & 259,2 & 0,0 \\
Anual & 606,0 & 196,0 & 512,7 & 0,32 & 1079,9 & 105,2 \\
\hline
\end{tabular}

Localizado na região nordeste, no semiárido o estado de Pernambuco, omunicípio de São Bento do Una, caracteriza-se por apresentar baixos índices pluviométricos (inferiores a 800 $\mathrm{mm}$ ), resultando em longos períodos de estiagem, que associado a fatores como as elevadas temperaturas e taxas evaporimétrica resultam na deficiência hídrica, pois normalmente nessa região a evapotranspiração é superior aos índices pluviométricos, tornando negativo o balanço hídrico (ANA, 2016). Este resultado corrobora com os do estudo aqui em discussões.

Girão (2004) em seu estudo mostrou que a "ação antropogênica sobre o ambiente natural vem promovendo inúmeras alterações, negligenciando-se a dinâmica ambiental como fatores reguladores dos complexos processos responsáveis pelo equilíbrio dos sistemas físicos". Estes resultados corroboram com as discussões aqui apresentados.

Em conformidade com os cálculos do balanço hídrico para o município em estudos tem-se que os anos que apresentaram somente reposição de água foram: 1950; 1951; 1952; 1956; 1958; 1959; 1960; 1961 1962; 1968; 1970; 1976; 1979; 1980; 1982; 1983; 1984; 1986; 1987; 1990; 1991; 1992; 1996; 1998; 2002; 2003; 2007; 2013; 2014 e 2015. Estas flutuações foram de baixas atuações dos sistemas provocadores de chuvas como ausência da Zona de convergência Intertropical (ZCIT), a não contribuição dos ventos alísios no transporte de vapor e umidade, flutuações térmicas elevadas nas temperaturas mínimas causando aumentos nos podres evaporativos, não foram registrados eventos extremos como: enchentes, alagamento registrando perda agrícola por volta de 40 a $60 \%$.

As variabilidades mensais e irregulares que se registrou nos excedentes hídricos foram ocasionadas pelos pulsos isolados da ZCIT, redução dos índices térmicos, auxílios dos ventos alísios na contribuição dos transportes de vapor e umidade podem ser verificadas nos anos de: 
1954; 1957; 1963; 1964; 1965; 1966; 1967; 1969; 1971; 1972; 1974; 1975; 1977; 1978; 1981; 1985; 1988 1989; 1994; 1995; 1997; 2000; 2001; 2002; 2004; 2005; 2006; 2008; 2009; 2010 e 2011. Os referidos excedentes hídricos não foram necessários e suficientes para provocarem evento extremos, o armazenamento de água não foram suficientes para sobre vivencia a partir do 5 meses, após o termino do período chuvoso.

\section{CONCLUSÕES}

A importância desse estudo em gerar subsídios para criação de medidas mitigadoras para a área de estudo em relação à avicultura, agropecuária, armazenamento e represamento de água através de cisternas enterrada de alvenaria, plástico, calçadão, tanque de pedra placas prémoldadas, barragens subterrânea, visando auxilio a população em geral.

As irregularidades pluviais estão diretamente interligadas aos sistemas provocadores de chuvas na região e ao fator de condensação.

Os impactos climáticos têm provocado modificações no balanço hídrico da região na última década, visto que irregularidade pluvial vem ocorrendo com fortes intensidades e de curta duração de tempo acarretando queda na produção avícola e agropecuária.

As contribuições locais como Zona de Convergência Intertropical, atuaram com intensidade e provocaram em suas maiorias chuva acima da normalidade em algumas décadas, registrando-se desastres de moderada a intensa proporção.

A elevação e a latitude são as variáveis fisiográficas que explicam melhor a variação da temperatura mensal e anual na área de estudo. As altas variabilidades das temperaturas contribuíram de forma positiva para as elevadas taxas de evapotranspiração.

As flutuações sazonais e interanual da temperatura mínimas decorrem das influências das estações do ano (variação sazonal) e da intensidade dos sistemas sinóticos atuantes, em cada ano, na época do período chuvoso e do período seco (variação interanual).

\section{REFERÊNCIAS}

ALMEIDA, H.A.; PEREIRA, F.C. Captação de água de chuva: uma alternativa para escassez de água. In: Congresso Brasileiro de Agrometeorologia, 15, Aracaju, SE, 2007, Anais..., Aracaju: CD-ROM.

AMORIM, R.C.F.; AMORIM, R.F.C.; AMORIM, D.K.F.; LEITE, C.C.; GOMES, H.B. Análise climática para a cidade de Curitiba/PR. In: congresso Brasileiro de Meteorologia, 13, Fortaleza, 2004. Anais...,Fortaleza, 2004.

ANA- Agência Nacional de Águas. Conjuntura dos Recursos Hídricos no Brasil, 2016. 
APAC. Agencia Pernambucana de Água e Clima do Estado de Pernambuco. 2017.

ARAGÃO, J.O.R. Um estudo das estruturas das perturbações sinóticas do Nordeste do Brasil. (INPE-789-TPT/017). Dissertação (Mestrado em Meteorologia), 1975.

ASSAD, E.D.; PINTO, H.S. Aquecimento global e a nova geografia da produção agrícola no Brasil. EMBRAPA-CEPAGRI, São Paulo, agosto, 82 p, 2008.

AVIPE- Associação de Avicultura de Pernambuco. 2005.

CAMPOS, C.G.C. Padrões Climáticos Atuais e Futuros de Temperatura do Ar na Região Sul do Brasil e Seus Impactos nos Cultivos de Pêssego e Nectarina. 2010. 191 f. Tese (Doutorado em Meteorologia) - Instituto Nacional de Pesquisas Espaciais, São José dos Campos, 2010.

COSTA, T.S.A.; COSTA FILHO, J.F.; BARACHO, D.C.; SANTOS, T.S.; MARINHO, E.C.S. Análise da temperatura do ar em Areia - PB, em anos de ocorrência de "El Niño". Apresentado no XVII Congresso Brasileiro de Agrometeorologia - 18 a 21 de Julho de 2011 - SESC Centro de Turismo de Guarapari, Guarapari - ES. 2011.

CAVALCANTI, E; CABRAL, J.; ALHEIROS, M. Desertificação: políticas públicas no semiárido brasileiro. In: GALVÃO, C.O.; CIRILO, J. A.; CABRAL, J.J.S.P.; MEDEIROS, M.G.A. Recursos hídricos para o semiárido: Abordagens por pesquisadores no Brasil, Portugal, Cabo Verde, Estados Unidos e Argentina. Porto Alegre: ABRH; Recife: Ed. Universitária da UFPE, p.463-489. 2011.

CAVALCANTI, E.P.; SILVA, V.P.R.; SOUSA, F.A.S. Programa computacional para a estimativa da temperatura do ar para a região Nordeste do Brasil. Revista Brasileira de Engenharia Agrícola e Ambiental, 10 (1), p. 140-147. 2006.

CAVALCANTI, E.P.; SILVA, E.D.V. Estimativa da temperatura do ar em função das coordenadas locais. In: Congresso Brasileiro de Meteorologia, 8, 1994. Belo Horizonte, Anais...,Belo Horizonte: SBMET, v.1, p.154-157. 1994.

CORREIA, M.F.; SILVA, F.S.; SILVA, A.M.R.S.; SANTOS, E.P.; MOURA, M.S.B. Impacto da expansão agrícola na amplitude térmica diária em ambiente semiárido. Ciência e Natura, v. Suplementar, p.311-314, 2011.

COSTA, M.N.M.; BECKER, C.T.; BRITO, J.I.B. Análise Das Séries Temporais De Precipitação Do Semiárido Paraibano Em Um Período De 100 Anos - 1911 A 2010. Revista Brasileira de Geografia Física. V. 06. N. 04. Pag. 680-696. 2013.

DANTAS, R.T.; NÓBREGA, R.S.; CORREIA, A.M; RAO, T.V.R. Estimativas das temperaturas máximas e mínimas do ar em Campina Grande - PB. In: Congresso Brasileiro de Meteorologia; Rio de Janeiro, 11. Rio de Janeiro. Anais...SBMET, p.534-537. 2000. 
FIETZ, C.R.; FRIZZONE, F.A.; FOLEGATTI, M.V. Probabilidade de ocorrência de períodos secos e chuvosos na região de Dourados, MS. Irriga (Botucatu), Botucatu, v.3, n.1, p.16-22, 1998.

FRANCO, R.M.B. 2007. Protozoários de veiculação hídrica: relevância em saúde pública. Revista Panamericana de Infectologia [online] 9. Disponível em: http://www.revistaapi.com/wpcontent/uploads/2014/02/mat-068.pdf>. Acesso. 2019.

GALVANI, E. Estatística descritiva em sala de aula. In: VENTURI, L. A.B. Geografia: Práticas de campo, laboratório e sala de aula. São Paulo: Editora Sarandi, 2011.

INMET. Instituto Nacional de Meteorologia. Normais Climatológicas do Brasil 1962-2016. Brasília, DF.

GIRÃO, O.; CORREA, A.C.B. A contribuição da geomorfologia para o planejamento da ocupação de novas áreas. Revista de Geografia, UFPE DCG/NAPA, Recife, v. 21, n. 02, 2004.

INTERGOVERNMENTAL PANEL ON CLIMATE CHANGE - IPCC. "Impacts, Adaptation and Vulnerability. Contribution of Working Group II to the Third assessment report of the Intergovernmental Panel on Climate Change". Cambridge University Press, Cambridge, 2001.

INTERGOVERNMENTAL PANEL ON CLIMATE CHANGE - IPCC. Summary for Policymakers. In: Climate Change 2013

LACERDA, F.F.; SILVA JÚNIOR, H.D.; ASSAD, E.D.; ASSIS, J.M.O.; MOURA, M.S.B. Extremos e variabilidade climática no Nordeste brasileiro e em Pernambuco In: Mudanças Climáticas e Impactos Ambientais / organizador Josicleda Domiciano Galvíncio - Recife : Ed. Universitária da UFPE, 342 p.1-23, 2010.

LAMEPE Laboratório meteorologia do estado de Pernambuco. 1998.

LIMA, K.C.; FERNÁNDEZ, J.P.R. A influência das anomalias de temperatura da superfície do mar e da topografia em dois eventos de precipitação intensa ocorridos no sudeste do Brasil. Engenharia Ambiental: Pesquisa e Tecnologia, Espírito Santo do Pinhal, v.8, n.1, p.309-319, 2011.

MARENGO, J.A. LINCOLN, M. ALVES, L.M.; VALVERDE, M.C.; LABORBE, R.; ROCHA, R.P. Eventos extremos em cenários regionalizados de clima no Brasil e América do Sul para o século XXI: Projeções de clima futuro usando três modelos regionais. Relatório 5, Ministério do Meio Ambiente - MMA, Secretaria de Biodiversidade e Florestas - SBF, Diretoria de Conservação da Biodiversidade - DCBio Mudanças Climáticas Globais e Efeitos sobre a Biodiversidade - Subprojeto: Caracterização do clima atual e definição das alterações climáticas para o território brasileiro ao longo do Século XXI. Brasília, fevereiro, 2007.

MCCABE, G.J.; MARKSTROM, S.L. A monthly water-balance model driven by a graphical user interface, p. 11, 2007. NOAA/ National Weather Service National Centers for 
Environmental Prediction Climate Prediction Center http://www.esrl.noaa.gov/psd/data/gridded/data.ncep. reanalysis.html (acesso 2019).

NOBRE, C.A.; ASSAD, E.D.O. "Aquecimento Global e o Impacto na Amazônia e na Agricultura Brasileira" - INPE Eprint: Disponível em: http://www.sid.inpe.br/ePrint@80 /2005/09.12.12.51 v.1. 2005.

MARENGO, J.A.; NOBRE, C.A.; CHOU, S.C; TOMASELLA; J.; SAMPAIO, G.; ALVES L. M.; OBREGON, G.O.; SOARES, W.R.; BETTS. R.; GILLIN, K. Riscos das Mudanças Climáticas no Brasil Análise conjunta Brasil-Reino Unidos sobre os impactos das mudanças climáticas e do desmatamento na Amazônia. 56p. 2011.

MARENGO, J.A.; CAMARGO, C.G. Trends in Extreme air temperatures in Southern Brazil, International Journal Climatology, v.28, p. 893-904, 2007.

MEDEIROS, R.M.; HOLANDA, R.M.; VIANA, M.A.; SILVA, V.P. climate classification in Köppen model for the State of Pernambuco - Brazil. Revista de Geografia (Recife). v.35, p.219 - 234, 2018.

MEDEIROS, R.M. Fatores provocadores e/ou inibidores de chuvas no estado de Pernambuco. 2017.

MEDEIROS, R.M.; BORGES, C.K.; VIEIRA, L.J. Análise climatológica da precipitação no município de Bananeiras - PB, no período de 1930-2011 como contribuição a Agroindústria In: Seminário Nacional da Agroindústria - V Jornada Nacional da Agroindústria, Bananeiras Paraíba. 2012,

NOGUEIRA, V.F.B.; CORREIA, M.F.; NOGUEIRA, V.S. Impacto do Plantio de Soja e do Oceano Pacífico Equatorial na Precipitação e Temperatura na Cidade de Chapadinha - MA. Revista Brasileira de Geografia Física, v.5, p.708 -724. 2012.

OMETTO, J.C. Bioclimatologia vegetal. São Paulo: Ceres, 440p. 1981.

PEDDE, S. C.; KROEZE, R. L. N. Escassez hídrica na América do sul: situação atual e perspectivas futuras. XX Simpósio Brasileiro de Recursos Hídricos. 2013.

PEREIRA, A.R.; ANGELOCCI, L.R.; SENTELHAS, P.C. Agrometeorologia: fundamentos e aplicações práticas. Agropecuária, 478p. 2002.

RUSTICUCCI, M.; BARRUCAND, M. Observed trends and changes in temperature extremes in Argentina. Journal Climate, v.17, p. 4099-4107, 2004.

SUDENE. Superintendência do Desenvolvimento do Nordeste - Dados pluviométricos mensais do nordeste - Série pluviometria 5. Estado do Pernambuco. Recife, 239p. 1990.

TRENBERTH, K.E., JONES, P.D.; AMBENJE, P.; BOJARIU, R.; EASTERLING, D.; KLEIN TANK, A.; PARKER, D.; RAHIMZADEH, F.; RENWICK, J.A.; RUSTICUCCI, M.; SODEN, B.; and ZHAI, P. Observations: Surface and Atmospheric Climate Change. In: Climate Change 
2007: The Physical Science Basis. Contribution of Working Group I to the Fourth Assessment Report of the Intergovernmental Panel on Climate Change [Solomon, S., D. Qin, M. Manning, Z. Chen, M. Marquis, K.B. Averyt, M. Tignor and H.L. Miller (eds.)]. Cambridge University Press, Cambridge, United Kingdom and New York, NY, USA. 2007. 